\title{
Medievalista
}

Online

$28 \mid 2020$

Número 28

\section{Materialidades e Devoções (sécs. V-XV)}

Materialities and Devotions (5th-15th centuries)

\section{Vincent Debiais}

\section{(2) OpenEdition}

\section{Journals}

\section{Edição electrónica}

URL: http://journals.openedition.org/medievalista/3413

DOI: $10.4000 /$ medievalista.3413

ISSN: 1646-740X

\section{Editora}

Instituto de Estudos Medievais - FCSH-UNL

Edição impressa

Paginação: 461-466

\section{Refêrencia eletrónica}

Vincent Debiais, «Materialidades e Devoções (sécs. V-XV)», Medievalista [Online], 28 | 2020, posto

online no dia 01 julho 2020, consultado o 25 março 2021. URL: http://journals.openedition.org/ medievalista/3413 ; DOI: https://doi.org/10.4000/medievalista.3413

Este documento foi criado de forma automática no dia 25 março 2021.

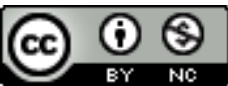

Mediavalista está licenciado com uma Licença Creative Commons - Atribuição-NãoComercial 4.0 Internacional. 


\title{
Materialidades e Devoções (sécs. V- $\mathrm{XV})$
}

\author{
Materialities and Devotions (5th-15th centuries)
}

\author{
Vincent Debiais
}

\section{NOTA DO EDITOR}

Texto originalmente publicado em 14/12/2019 no blogue de visu - cultures visuelles $d u$ Moyen Âge en perspectives, consultável em: https://devisu.hypotheses.org/351. Tradução de Miguel Metelo de Seixas (IEM - NOVA FCSH).

1 Entre os dias 6 e 9 de Novembro de 2019, teve lugar no Mosteiro da Batalha (Portugal) um vasto congresso dedicado ao tema "Materialidades e Devoções". Reunindo mais de sessenta investigadores provindos de uma dúzia de países diferentes, este evento muito concorrido propôs aos participantes o questionamento da dimensão objectal da relação com o divino no contexto de uma longa Idade Média, percorrendo, de leste a oeste e de norte a sul, uma extensa Europa. Foi uma oportunidade para descobrir ou redescobrir imagens e artefactos que medeiam ou traduzem várias formas de devoção.

2 Livros, cálices, móveis, tectos, pinturas monumentais, vestes, amuletos, túmulos, relicários, letreiros. Os cerca de 2.000 diapositivos que desfilaram durante quatro dias pelos auditórios do mosteiro da Batalha não esgotaram decerto a diversidade material da Idade Média, mas permitiram apreciar a variedade dos materiais utilizados, das técnicas dominadas, dos conhecimentos mobilizados e, mais geralmente, dos meios humanos e económicos envidados para produzir os objectos postos em acção no contexto das devoções medievais. Esta inesgotável diversidade de formas requer o uso da forma plural para todos os descritores de tais fenómenos: devemos falar de devoções, religiosidades, liturgias, experiências rituais que ocorrem em contextos culturais e sociais precisos, determinados por uma série de factores históricos que não podem ser reduzidos a um modelo único de relações entre objecto e devoção. 
3 Não era intenção dos organizadores do colóquio da Batalha, naturalmente, propor tal análise estrutural, que empobreceria necessariamente a especificidade do discurso em imagens, a empatia própria de cada acto de devoção, as condições particulares - porque sociais - dos rituais medievais. Por esta razão, Miri Rubin (Queen Mary, University of London), na conferência plenária que pronunciou, teve o cuidado de não "concluir" o colóquio, preferindo apresentar um exercício de autocrítica em relação ao seu importante livro Corpus Christi. The Eucharist in Late Medieval Culture (Cambridge, 1991) mediante o prisma das tendências historiográficas actuais: a activação dos sentidos, o género de práticas devocionais, uma abordagem antropológica da liturgia, a dimensão performativa dos rituais, a espacialidade e os objectos de culto...

Este balanço pleno de pistas ainda por explorar no estudo da cultura material medieval veio, de forma geral, revelar a forma como o material turn tem tendido - e por vezes continua a fazê-lo - a esvaziar dois aspectos que são, no entanto, fundamentais na relação com o divino. 0 primeiro diz respeito à dissimulação do social pelo material. Poder-se-ia esperar que a atenção dada aos objectos, ao seu valor, ao seu significado, à sua função, conduzisse a investigação para o ser humano que encomenda, fabrica, vende, compra, manipula, conserva, destrói, transmite o artefacto; esperar-se-ia finalmente uma incorporação do objecto na esfera social e a sua instituição nas relações entre indivíduos e grupos: relações comerciais, relações de poder, relações estéticas... Contudo, as comunicações apresentadas na Batalha mostraram que tal raramente acontece: as imagens, as formas colectivas ou individuais de devoção, os objetos existiriam por si próprios, desencarnados, instrumentos fora-de-solo de práticas capazes de dispensar qualquer ancoragem no mundo vivido. Em semelhante contexto, o manuscrito não precisa nem de leitor nem escriba, tal o livro cerimonial dispensa qualquer liturgia, a imagem qualquer espectador, o relicário qualquer relíquia, a igreja qualquer comunidade, o material quaisquer propriedades. 0 segundo esvaziamento diz respeito à dimensão espiritual da relação dos objetos com o divino. A atenção prestada à cultura material da prática religiosa amputa a dimensão transcendente de tal experiência. A devoção, a contemplação, a oração, a meditação, quando consideradas por via dos objectos e das imagens que as medeiam, vêem-se amiúde reduzidas a uma acção desprovida de efeito, ou então a uma eficácia de ordem mágica. Tudo acaba por se passar como se a cultura material não pudesse conter em suas formas as intenções espirituais dos homens e das mulheres da Idade Média. O recurso ao conceito de affordance, formulado no final dos anos 70 por James Gibson, entre outros, permite-nos por um lado pensar o objecto e o homem nas possibilidades das suas interacções, mas acaba por reduzir a função da cultura material a quanto ela autoriza no campo mecânico; desaparece de tal análise, logo, tudo quanto ela induz necessariamente no campo imaterial da relação com o transcendente, a qual, devido ao seu carácter inefável, se torna, portanto, resistente à abordagem historiográfica.

Estas duas tendências - o objeto como extra-social e o objeto como uma intranscendência - constroem de facto uma abordagem museográfica das materialidades; artefactos pensados sem contexto e sem efeito, exibidos na vitrine de uma abordagem abertamente dessacralizada; uma colecção de objectos que são apenas rasto e traço de si próprios, que não se reenviam a nada que possa, de uma ou outra forma, escapar ao historiador. Esta é uma visão assaz redutora - e, portanto, falsa - do que a antropologia histórica tem permitido tirar da exploração das fontes materiais da Idade Média. E foi sobre isto, aliás, que Jean-Claude Schmitt (École des hautes études en sciences sociales, 
Paris) insistiu na sua palestra inaugural. Tal como Miri Rubin - é interessante notá-lo de um ponto de vista retórico e heurístico - Jean-Claude Schmitt optou também por comentar um trabalho essencial sobre esta questão da ligação entre materialidades e devoções, o livro Christian Materiality de Caroline Walker Bynum (New York, 2011). Este orador situou, assim, o paradigma da Encarnação no centro da ligação entre visível e invisível, não separando, na relação com o real, quanto releva da experiência dos sentidos (o ritmo marcado pelos sinos, o contacto das imagens...) e da transcendência que ela sinaliza.

6 Claro que é caricatural extrair de tal forma estas duas tendências do programa riquíssimo do colóquio, e as comunicações apresentadas na Batalha proporcionaram de facto muitas pistas de investigação para pensar as devoções medievais. Entre tais pistas, podem assinalar-se três temáticas transversais. A primeira diz respeito aos fenómenos do efémero. A concepção museográfica dos objectos leva-nos, por inércia, a pensar neles num quadro de estabilidade e permanência que é, na realidade, estranho à encenação destes objectos e imagens. É preciso, pelo contrário, considerar uma alternância entre exposição e confinamento, entre manipulação e repouso, entre instalação definitiva e mostra temporária. A cultura material, inclusive na sua utilização devocional, assume uma fluidez de princípio que se manifesta de forma evidente nas cerimónias pontuais da liturgia (paramento do altar, instalação de "decoração", alternância das cores litúrgicas), mas que se manifesta também noutros domínios (deposições funerárias de objectos litúrgicos, transformação de objectos quotidianos em "relíquias", entesouramento de manuscritos). A segunda temática transversal é a da tensão entre símbolo e instrumento. Várias comunicações insistiram no facto de que os objectos e as imagens manipulados no quadro das práticas devocionais não passavam afinal de símbolos, sinais tangíveis de uma entidade inatingível da qual eles manifestavam desde logo a existência, e em seguida a presença no mundo sob uma determinada forma: o crucifixo para Cristo, o relicário para o respectivo santo, o vinho para o sangue, o livro para a palavra. Ao mesmo tempo, estes sinais constituem os instrumentos do procedimento devocional, que permite atingir pela mediação dos sentidos aquilo que está fora de si, fora do mundo. Ora, tal tensão vem interrogar o estatuto do próprio objecto: o cálice permanece cálice fora do sacrifício eucarístico? o que dizer das imagens pintadas num manuscrito quando o livro se encontra fechado? É esta tensão que subjaz ao conceito de agency de Alfred Gell quando descreve o processo de virtuosidade activo na eficiência do objecto. 0 que nos leva à terceira temática, que diz respeito à dimensão multimodal dos objectos de devoção que operam sempre na matéria e simultaneamente além dela, mobilizando diversos sentidos, gestos, movimentos, para a elaboração de discursos complexos. A devoção apresenta-se, assim, ligada por natureza ao conceito de performance que coloca o objecto em relação com aquilo que ele permite atingir. A multiplicação das impressões materiais da devoção (insígnias de peregrinação, imagens votivas, medalhas, ex-votos) testemunha a necessidade de apropriação de objecto e imagem, de incorporá-la, de transformar a matéria em corpo, por fim, na prática devocional, numa espécie de gigantesca analogia cristã do processo eucarístico.

o quadro monumental do mosteiro da Batalha forneceu um eco peculiar a estas questões históricas e antropológicas. Uma organização sem mácula, debates de bom nível e trocas intensas contribuíram para que estas jornadas decorressem num clima estimulante. No final, o conceito de objecto ou de imagem devocional continua a 
alimentar muitas questões quanto à sua pertinência para as culturas cristãs do Ocidente medieval e para as suas traduções na matéria e no visual.

\section{AUTOR}

\section{VINCENT DEBIAIS}

École des Hautes Études en Sciences Sociales, Centre de Recherches Historiques, Anthropologie Historique du Long Moyen Âge 75006 Paris, France. vincent.debiais@ehess.fr. https://orcid.org/ 0000-0002-3397-4421 